\title{
Intermédialités
}

Histoire et théorie des arts, des lettres et des techniques

Intermediality

History and Theory of the Arts, Literature and Technologies

\section{Le pacte photographique}

Quelques autofictions d'André Martin

\section{Olivier Asselin}

Numéro 2, automne 2003

Raconter

Telling

URI : https://id.erudit.org/iderudit/1005462ar

DOI : https://doi.org/10.7202/1005462ar

Aller au sommaire du numéro

Éditeur(s)

Centre de recherche sur l'intermédialité

ISSN

1705-8546 (imprimé)

1920-3136 (numérique)

Découvrir la revue

Citer ce document

Asselin, O. (2003). Le pacte photographique : quelques autofictions d'André

Martin. Intermédialités / Intermediality, (2), 156-159.

https://doi.org/10.7202/1005462ar d'utilisation que vous pouvez consulter en ligne.

https://apropos.erudit.org/fr/usagers/politique-dutilisation/ 


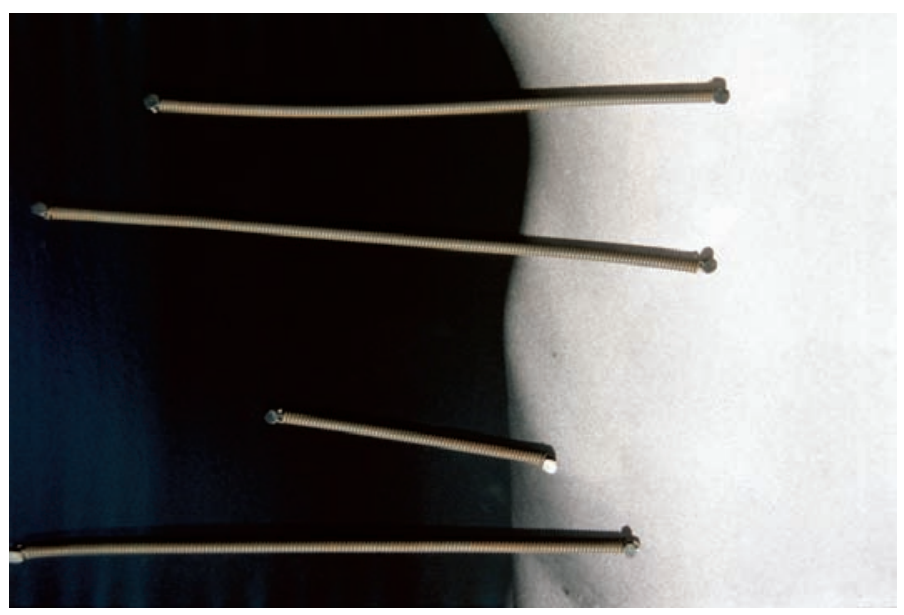

André Martin, Mes modèles — Leurs portraits, 2002, épreuve par procédé chromogène, cordes de piano, 48 " diamètre (détail). 


\title{
Le pacte photographique Quelques autofictions d’André Martin
}

\author{
OLIVIER ASSELIN
}

D ans l'une des nouvelles qui composent ses Crimes passionnels. Cinq faits divers photographiques (1992), André Martin élabore une singulière autofiction. Ce récit met en scène l'artiste lui-même, son modèle et un admirateur, en un étrange triangle amoureux, qui se rompt finalement, sur la mort, par le meurtre du modèle par l'admirateur.

On avait trouvé Hermann sur le sol de la cuisinette sept dagues enfoncées dans chacune des étoiles tatouées, le corps entièrement recouvert de cirage à chaussure noir. L’assassin avait écrit sur le sol: «La photo menteuse». Il avait placé les mains de la victime en croix sur le cœur. On avait cru à un acte de démence et l'assassin n’avait pas été retrouvé. Naturellement, j'avais deviné son identité mais je n'ai pu me soumettre à l'idée de dénonciation. Après tout, il s'agissait de mon admirateur. Ayant perdu mon modèle étoilé et mon unique admirateur je renonçai définitivement ce jour-là à la photographie ${ }^{1}$.

Et le récit se conclut comme il se doit, par une photographie, qui montre le détail d'un corps, une plaie ouverte en gros plan. Par sa précision tout objective, l'image rappelle la photographie judiciaire, les documents de la médecine légiste. Mais elle évoque aussi la peinture religieuse, toutes ces représentations du Christ au flanc percé, en particulier celle du Caravage, où Thomas, doutant de la résurrection, pose son doigt sur la plaie de Jésus.

Ce récit illustré - à moins que ce soit une photographie narrativisée - est exemplaire de toute l'œuvre de Martin. Dans ses livres et ses installations, l'artiste fait toujours dialoguer le texte et l'image, le récit et la photographie. On pourrait penser que le récit est toujours fictif et la photographie, toujours

1. André Martin, Crimes passionnels. Cinq faits divers photographiques, Montréal, Éditions Heinrich Fitzback, 1992, p. 24-26. 
factuelle, mais les œuvres de Martin font travailler ces croyances, puisque le récit y est souvent largement autobiographique et la photographie, généralement mise en scène. Souvent, le récit est au je, le narrateur est identifié à l'auteur, il a le même nom, la même profession, la même œuvre, les mêmes expositions, la même carrière. Inversement, les images sont théâtrales, les corps morts et blessés des Crimes passionnels sont des modèles, savamment maquillés, les personnages de Mes modèles - Autoportrait (2000) ou de Mes modèles Leurs portraits $(2002)^{2}$ posent explicitement, ils sont tous présentés pareillement, nus, agenouillés, de dos, dans un espace éclairé mais indistinct ou dans l'obscurité devant un écran enduit de phosphore. Et ainsi, dans cette dialectique incessante, la photographie est fictionnalisée et le récit, factualisé, nous nous mettons à douter de la première et à croire au second.

De plus, comme cette nouvelle des Crimes passionnels, les œuvres de Martin mettent toujours en scène l'artiste, le modèle et le spectateur. Elles ne se contentent pas de représenter le processus artistique dans une mise en abîme comme le faisaient certaines œuvres classiques, ni de le présenter par un ensemble d'indices (au sens peircien) comme le font certaines œuvres postmodernes, mais bien de faire à la fois l'un et l'autre et, surtout, de le fictionnaliser, de romancer la production et la réception de l'art. Dans ces fictions, les rapports entre l'artiste, le modèle et le spectateur sont complexes: ils sont analogues deux à deux, ils sont ambivalents et, par conséquent, réversibles - à l'infini.

La relation entre l'artiste et son modèle est présentée comme le modèle de toutes les relations et en particulier de la relation entre le spectateur et l'œuvre. En effet, la production de l'image photographique met en jeu un sujet regardant et un corps regardé, un dispositif voyeuriste, apparemment asymétrique, médiatisé par l'appareil photographique, attesté par l'image photographique. Mais, comme dans le dispositif de la peinture en perspective, la réception de l'image répète sa production: le spectateur vient occuper la place même de l'artiste en regard du modèle. Les œuvres de Martin soulignent constamment cette analogie en opacifiant le dispositif spectatoriel, comme dans Mes modèles Autoportrait, où les photographies sont placées à l'intérieur de cônes de métal percés d'œilletons, qui reprennent la structure de la camera obscura (fig. 1). Comme le modèle s'offrait au regard de l'artiste, l'artiste s'offre maintenant au regard du spectateur - à travers son œuvre.

2. L'exposition Mes modèles - Autoportrait a été présentée au Musée d'art contemporain de Montréal, du 11 mai au 13 août 2000 et Mes modèles - Leurs portraits, à la Galerie Circa à Montréal, du 19 octobre au 16 novembre 2002. 


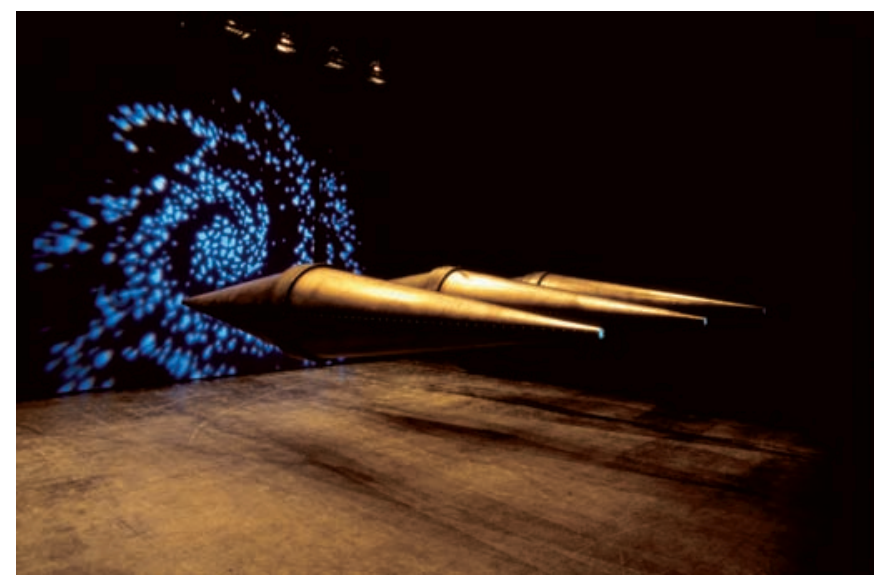

André Martin, Mes modèles - Autoportrait, 2000, vue de l'installation.

Mais cette relation entre l'artiste et son modèle est aussi ambivalente. Il s'y mêle toutes sortes de sentiments, beaucoup de désir, certes, mais aussi, parfois, un certain ressentiment. Dans les œuvres de Martin, le modèle est clairement l'objet du désir - dans certains récits, le modèle devient même l'amant. Mais il est souvent aussi maltraité. Non seulement est-il soumis au rituel photographique, mais encore il est exhibé - il est détaillé par le gros plan ou alors il est présenté nu, agenouillé, replié sur lui-même, le visage caché. Parfois, il devient une simple surface d'inscription, comme dans Mes modèles - Autoportrait, où l'artiste écrit des mots sur la peau du modèle avec un pointeur laser. Parfois, son image est attaquée, comme dans Mes modèles - Leurs portraits, où la photographie elle-même est souillée de viscères ou trouée, littéralement, comme par des balles. Et parfois encore, dans la fiction, le modèle est même agressé, comme dans les Crimes passionnels, où, par les moyens du maquillage et les pouvoirs de l'écriture, il est meurtri et finalement assassiné.

Comme aujourd'hui la vidéo numérique, la photographie a pu, un temps au moins, paraître anti-narrative et surtout anti-fictionnelle. Les artistes de l'époque l'ont assez dit: par sa définition même, qui reproduit toutes les choses également, avec la même précision, elle semble ne rien pouvoir laisser à l'imagination et empêcher toute rêverie. Les œuvres d'André Martin redécouvrent le potentiel narratif et fictionnel de la photographie. En la mettant en scène, en exploitant son aura d'image indicielle, en la faisant dialoguer avec le texte, ces livres, ces installations ouvrent l'image sur le hors-champ - au récit, à la fiction, au fantasme. 